Revista de Derecho de la Pontificia Universidad Católica de Valparaíso

LIV (Valparaíso, Chile, 1er semestre de 2020)

[pp. 217 - 224]

\title{
¿Puede ser imprudente CONFIAR de Forma RAZONABLE? COMENTARIOS A PROPÓSITO DE LA EXPOSICIÓN DE LA VÍCTIMA AL DAÑO DURANTE EL PERIODO PRECONTRACTUAL
}

[Can be reckless to trust reasonably? Comments concerning the victim's exposure to damage during the pre-contractual period]

\section{Hernán CORTEz LÓPEZ*}

ReCibido el 14 de agosto de 2019 y Aprobado el 9 de julio de 2020.

\section{INTRODUCCIÓN}

La participación del afectado en la producción del daño es una condición necesaria del perjuicio, al punto que sin esta el daño no podría acaecer y, por tanto, no habría lugar a la reparación ${ }^{1}$.

En materia de responsabilidad precontractual, la participación de la víctima se manifiesta a través del riesgo que esta asume al iniciar negociaciones con un tercero en miras a celebrar un contrato en el futuro. Con todo, no por asumir un riesgo debe considerarse sin más que el actuar de la víctima es imprudente, atendido que la confianza que las partes depositan en el periodo precontractual descansa en las exigencias de la buena fe que impera durante todo el iter contractual ${ }^{2}$.

Las sentencias objeto de este comentario resultan especialmente interesantes para dilucidar este punto, toda vez que se discute si es posible considerar como una exposición imprudente al riesgo (a modo de determinar si corresponde disminuir el monto a indemnizar por aplicación del artículo 2330 del Código Civil) participar en negociaciones sin contar con

* Abogado. Magíster en Derecho Civil Patrimonial y Diplomado en Derecho del Consumo, Universidad Diego Portales. Correo electrónico: hernan.cortez@mail. udp.cl.

${ }^{1}$ Domínguez, Ramón, El hecho de la víctima como causal de exoneración de responsabilidad civil, en Revista de derecho Universidad de Concepción 136 (1966), p. 30.

${ }^{2}$ San Martín, Lilian, Responsabilidad precontractual por ruptura injustificada de negociaciones, en Revista Chilena de Derecho 40 (2013), 1, p. 321. 
asesoría experta, en atención a la buena fe y la confianza razonable que la contraparte generó en el demandante.

Para el análisis de estas sentencias, me referiré brevemente al supuesto de hecho del artículo 2330 del Código Civil y su aplicación cuando el daño se ha producido en el periodo precontractual. Para luego atender a la fundamentación otorgada en la sentencia de la Corte de Apelaciones de Santiago (dictada el 17 de octubre de 2014, Rol No 3918-2013), y en la sentencia de la Corte Suprema (dictada el 9 de diciembre de 2015, Rol N ${ }^{\circ}$ 710-2015), ambas caratuladas "Flores Clunes con Parque Arauco S.A.”.

\section{LOS HECHOS}

Durante el año 2000 se publicaron anuncios en diarios de circulación nacional que invitaban a profesionales de la carrera de medicina a invertir en el proyecto "Arauco Médica Maipú”. El cual tenía por objeto la construcción de una clínica en un terreno adyacente al Mall Arauco Maipú, de propiedad de la empresa Constructora y Administradora Uno S.A, filial de Parque Arauco S.A., que autorizó la utilización de su logo en la difusión publicitaria del proyecto de la futura clínica ${ }^{3}$.

Dicha publicidad despertó el interés de un grupo de inversionistas, para quienes el respaldo de Parque Arauco S.A. al proyecto fue una condición determinante para participar, atendido el prestigio y patrimonio que ostenta dicha sociedad. Decidiendo realizar un aporte de capital de 10 millones de pesos cada uno, tras una serie de reuniones promocionales llevadas a cabo en las dependencias de Parque Arauco.

No obstante, con posterioridad Parque Arauco S.A. anunció que su participación se limitaba al arriendo del terreno, excluyéndose de cualquier responsabilidad en la ejecución del proyecto.

Frente a esta situación los aludidos inversionistas deciden demandar a Parque Arauco S.A. por los perjuicios patrimoniales y extrapatrimoniales que les habría provocado la conducta de la empresa, consistente en no informar oportunamente sus verdaderos intereses en el negocio durante el periodo precontractual, y haber generado la ilusión de ser parte del proyecto al participar activamente en la difusión de este.

La sentencia de primera instancia rechazó la demanda. Dicha decisión fue revocada por la Corte de Apelaciones de Santiago, que acogió la pretensión de los demandantes, pero con reducción de un 50\% de los perjuicios

${ }^{3}$ En el contrato de arrendamiento del terreno celebrado entre Arauco Medica Maipú y Mall Arauco Maipú, se incluía una cláusula mediante la cual se facultaba la utilización del logo de Parque Arauco S.A. en la publicidad y difusión del proyecto. 
avaluados por aplicación del artículo 2330 del Código Civil, al estimar imprudente negociar sin contar con la asesoría de profesionales expertos en el área de inversión en que se involucraron los afectados.

Finalmente, la Corte Suprema acogió el recurso de casación en el fondo interpuesto por los demandantes, determinando la errónea aplicación del artículo 2330 del Código Civil, atendida la confianza razonable que el demandado habría generado hacia los inversionistas, y al principio de buena fe.

La exposición imprudente al daño en el periodo precontractual en determinadas circunstancias, la reparación que debe concederse en atención a los perjuicios avaluados puede estar sujeta a reducción ${ }^{4}$, como es el caso de la exposición imprudente de la víctima al daño, según dispone el artículo 2330 del Código Civil.

Dicha norma no contempla una exoneración de responsabilidad provocada por la interrupción del vínculo casual, sino solo una rebaja en la cuantía del resarcimiento atendida la participación convergente de victimario y víctima, configurado así un fenómeno de concausas 5 . Siempre que la intervención de la víctima se realizara de forma culpable.

Esta norma no solo se aplica a los supuestos de responsabilidad en que el daño proviene de un ilícito por parte del victimario con quién la víctima no se relaciona hasta el acaecimiento del hecho, sino también a los daños derivados de ilícitos precontractuales, a propósito de los cuales la postura de la doctrina nacional ha sido la aplicación del régimen extracontractual de responsabilidad 6 .

En estos casos, la responsabilidad encuentra su fundamento en la inobservancia de las exigencias de la buena fe objetiva que derivan en el quebrantamiento de la confianza razonable creada en la contraparte ${ }^{7}$, siempre que quien causa el daño carezca de justificación y se reúnan los demás requisitos que hacen procedente la responsabilidad civil.

Es el caso objeto de este comentario, los demandantes alegan los per-

${ }^{4}$ Corral señala como supuestos en que procede la reducción: (i) Las disposiciones legales especiales, (ii) La culpa de la víctima, (iii) La falta del deber de mitigar el daño de esta, y (iv) la compensación del lucro obtenido. A los cuales Barcia, refiriéndose al derecho comparado, agrega el estado de necesidad. Ver Corral, Hernán, Lecciones de responsabilidad civil extracontractual (Santiago, Editorial LegalPublishing, 2013), pp. 380-383; y BARCIA, Rodrigo, Lecciones de derecho civil (Santiago, Editorial Jurídica de Chile, 2014), II, p. 254.

${ }^{5}$ Bahamondes, Claudia - Pizarro, Carlos, La exposición de la víctima al daño: desde la culpabilidad hasta la causalidad en Revista de derecho de la Pontificia Universidad Católica de Valparaíso 33 (2012), pp. 41-42.

${ }^{6}$ SAN MarTín, cit. (n. 2), p. 320.

${ }^{7}$ SAN MarTín, cit. (n. 2), p. 323. 
juicios provocados por la falsa imagen creada por Parque Arauco S.A., que los llevó a pensar que ésta era parte del proyecto y, en definitiva, a invertir en el mismo.

Tanto la Corte de Apelaciones de Santiago como la Corte Suprema, coincidieron en determinar la responsabilidad del demandado (atendida la apariencia que generó al permitir que su logo y local comercial se utilizaran para la difusión del proyecto, en la cual los demandantes confiaron razonablemente), pero discrepan respecto a la procedencia de la aplicación del artículo 2330 del Código Civil. A continuación, se analizan ambos fallos en apartados separados.

\section{Sentencia de la Corte de Apelaciones}

La Corte de Apelaciones califica de imprudente el actuar de los inversionistas bajo el argumento que se cita a continuación:

"La apreciación del daño está sujeta a reducción, si el que lo ha sufrido se expuso a él imprudentemente (...) estos sentenciadores estiman que pese a que resulta evidente la falta de cuidado con la que actuó la demandada con ocasión de la promoción del proyecto Arauco Médica Maipú, al desentenderse de las consecuencias que su desempeño y participación en el mismo podrían acarrear al bienestar general de terceros interesados, no puede tampoco desconocerse que asistió también a los demandantes negligencia en su conducta, al menos al no hacerse asesorar por profesionales que conocieran el área de inversión en la que se involucraron, exponiéndose de este modo, en criterio de esta Corte, imprudentemente al daño, por lo que se reducirá en un cincuenta por ciento la apreciación de los perjuicios anteriormente avaluados (...)'s.

A propósito del extracto citado, es posible formular tres observaciones que nos llevan a rechazar la solución al caso en comento.

En primer lugar, la Corte no explicita las razones que motivan que el monto de la rebaja sea un $50 \%$ los perjuicios avaluados, por lo que pareciera que el razonamiento del tribunal descansa en una comprensión estricta de la noción de concausa, bajo la influencia de la teoría de la equivalencia de las condiciones, ya que tanto el agente como la víctima han sido causantes en la misma medida del perjuicio, por lo que la división del monto indemnizatorio debe ser soportado en partes iguales?.

Esta solución nos parece incorrecta atendido que, como señala Domínguez, resulta más justo y racional realizar una división en consideración a

\footnotetext{
${ }^{8}$ Considerando décimo octavo de la sentencia de la Corte de Apelaciones de Santiago. Énfasis agregado.

${ }^{9}$ Domínguez, cit. (n. 1), p. 46.
} 
la influencia causal de cada culpa en la producción del daño ${ }^{10}$, y no una basada en criterios salomónicos.

En segundo lugar, la Corte señala que el solo hecho de haber invertido sin asesoría de profesionales permite concluir que la víctima se expuso imprudentemente al daño.

Dicha interpretación sugiere que la regla general es que las partes negocian de mala fe, siendo la asesoría una condición indispensable para evitar abusos como el de este caso, por lo que la falta de esta sería un acto culpable e imprudente de la víctima, que se expuso culpablemente a un riesgo.

Finalmente, la argumentación de la Corte para construir el supuesto del artículo 2330 en el considerando citado, resulta contradictorio con lo señalado en el considerando décimo cuarto de la misma sentencia, en el cual se señala que si no fuera por el soporte prestado por Parque Arauco los demandantes no hubieran participado en el negocio o lo hubieran hecho con mayor resguardo ${ }^{11}$.

Es decir, del mencionado considerando décimo cuarto se desprende que la única causa del perjuicio fue la expectativa que generó el demandado sobre un determinado aspecto del negocio. Sin la cual los demandantes jamás hubieran contratado, o no lo hubieran hecho sin asesoría.

Si ese es el caso, es incompatible sostener que la demandada generó una confianza razonable que determinó que se negociara sin asesoría, y al mismo tiempo alegar una exposición imprudente por parte de las víctimas, ya que si se suprime el comportamiento de la empresa el perjuicio no se hubiera producido. Por lo tanto, no se trata de un supuesto de concausas, y no es posible atribuir culpa al actuar de los afectados.

\section{Sentencia de la Corte Suprema}

Por su parte, la Corte Suprema acoge el recurso de casación en el fondo presentado por los emandantes, entendiendo que la confianza razonable

${ }^{10}$ Domínguez, cit. (n. 1), p. 47. En el mismo sentido Barros, Enrique, Tratado de responsabilidad civil extracontractual (Santiago, Editorial Jurídica de Chile, 2006), p. 436.

${ }^{11}$ En este se señala: “(...) estos sentenciadores estiman que los perjuicios que alegan haber sufrido los actores fueron causados precisamente a raíz de la confianza que les generó la conducta activa y omisiva de la demandada desarrollada de la forma precedentemente reseñada, puesto que de no haber mediado aquélla los demandantes no habrian convenido en participar en el negocio que se les proponia o lo habrian hecho con especiales resguardos que desatendieron en este caso (...)". Considerando décimo cuarto de la sentencia de la Corte de Apelaciones. 
de los inversionistas permite descartar que su actuar fuera imprudente. De esta forma, señala la Corte:

"Que conforme ha quedado establecido en el proceso los demandantes en su actuar estuvieron guiados por la confianza y buena fe que les producía entender que la demandada era quien participaba y respaldaba el negocio, la aparente solvencia de ésta fue la suficiente garantía para que los demandantes decidieran invertir sus dineros en la iniciativa referida, la que por lo demás se vinculaba directamente con la profesión liberal que cada uno de ellos ostentaba, por lo tanto no resulta exigible a éstos contar con una asesoría especializada, porque como se señaló previamente la demandada omitió entregar una información básica para los actores, la que para ser comprendida no requería de la asistencia de un especialista, sino que bastaba solo un actuar claro y diligente de la demandada"12.

Finalmente señala la Corte:

“(...) conforme al escenario antes descrito no resulta posible calificar que la conducta de las victimas fuese imprudente, puesto que los hechos establecidos de acuerdo al mérito del proceso no permiten concluir que los demandantes necesariamente hayan debido prever que se les estaba ocultando información relevante respecto de quienes eran los que respaldaban el negocio propuesto y las características reales del mismo. En consecuencia, como los afectados no estaban en condiciones ciertas de evitar el daño, no puede concluirse que hayan contribuido a su producción (...)"r3.

La solución de la Corte Suprema establece directrices sobre la materia que resulta importante destacar.

En primer lugar, entiende que el actuar de los inversionistas fue guiado por la confianza razonable y la buena fe, lo que determina que no sea exigible a estos contar con asesoría especializada, ya que solo confiaron en las expectativas razonables generadas por Parque Arauco S.A.

En segundo lugar, agrega que la confianza razonable permite descartar la imprudencia en el actuar de los afectados, ya que estos no se encontraban en condiciones de evitar el daño, ya que este se produjo por una omisión del demandado, al no informar aspectos básicos del negocio en el que participaron los inversionistas.

Es decir, la decisión de la Corte Suprema descansa en la idea de que no se trata de un supuesto de concausas, ya que la decisión de invertir fue motivada de forma exclusiva por la conducta de Parque Arauco S.A., no

\footnotetext{
${ }^{12}$ Considerando vigésimo tercero de la sentencia de la Corte Suprema.

${ }^{13}$ Considerando vigésimo cuarto de la sentencia de la Corte Suprema. Énfasis agregado.
} 
debiendo ser considerada la de los afectados al ser una consecuencia del actuar de la empresa.

Junto con lo anterior, se establece que la confianza razonable permite descartar la imprudencia o culpa en el actuar de la víctima, teniendo en consideración el principio de buena fe.

En efecto, atendidas las exigencias de este principio debe descartarse que las partes deban, por regla general, desconfiar de las expectativas generadas por la contraparte, siempre que estas puedan ser consideradas razonables en atención a la calidad de las partes, y de los actos y omisiones de estas durante el periodo precontractual.

En este caso, como advierte el tribunal, las partes no necesitaban contar con asesoría especializada, atendido que la iniciativa se vinculaba directamente con la profesión liberal que cada uno de ellos ostentaba. Siendo razonable que estos confiaran en la imagen creada al utilizarse el logo e instalaciones de Parque Arauco S.A., sumado a la omisión de la sociedad de informar la extensión de su participación en el proyecto.

De esta forma, se descarta el argumento que llevó a la Corte de Apelaciones a disminuir el monto a indemnizar, por lo que la asesoría de profesionales especializados solo sería necesaria si lo que los inversionistas esperaban del negocio fuera algo distinto a lo que la contraparte les hizo creer. Como si esperaran una ganancia mayor a la que se les promete, por ejemplo.

\section{CONClusiones}

El supuesto de reducción del monto a indemnizar regulado en el artículo 2330 del código Civil supone un actuar culpable de la víctima que permita configurar un supuesto de concausas. Estimando la Corte de Apelaciones de la sentencia que se comenta, que estos requisitos concurren en este caso, aun cuando el actuar de los afectados fue determinado exclusivamente por la conducta del demandado.

El razonamiento de la Corte Suprema permite superar la contradicción advertida en el razonamiento de la Corte de Apelaciones, al descartar la posibilidad de atribuirles culpa o participación a los inversionistas en el acaecimiento del daño, cuando esté deriva exclusivamente de la confianza razonable creada por la contraparte.

En efecto, la confianza razonable supone un análisis con cierta diligencia de la información presentada durante el periodo precontractual, pero no un deber de autocuidado que determine que deba desconfiarse de la apariencia generada por la contraparte a través de ciertas afirmaciones o conductas durante el periodo precontractual, que generan expectativas razonables sobre un determinado aspecto del negocio. 


\section{BiBLIOGRAFÍA}

BARCIA, Rodrigo, Lecciones de derecho civil (Santiago, Editorial Jurídica de Chile, 2014), II.

BARros, Enrique, Tratado de responsabilidad civil extracontractual (Santiago, Editorial Jurídica de Chile, 2006).

Bahamondes, Claudia - Pizarro, Carlos, La exposición de la víctima al daño: desde la culpabilidad hasta la causalidad, en Revista de derecho de la Pontificia Universidad Católica de Valparaíso 32 (2012).

CORRAL, Hernán, Lecciones de responsabilidad civil extracontractual (Santiago, Editorial Legal Publishing, 2013).

Domínguez, Ramón, El hecho de la víctima como causal de exoneración de responsabilidad civil, en Revista de derecho Universidad de Concepción 136 (1966).

SAN MARTín, Lilian, Responsabilidad precontractual por ruptura injustificada de negociaciones, en Revista Chilena de Derecho 40 (2013), 1.

\section{JURISPRUDENCIA CITADA}

Flores Clunes con Parque Arauco S.A. (2014): Corte de Apelaciones de Santiago, 17 de octubre de 2014, Rol No 3918-2013, disponible [en línea]: Legal Publishing CL/JUR/7699/2014.

Flores Clunes con Parque Arauco S.A. (2015): Corte Suprema, 9 de diciembre de 2015, Rol Nº710-2015, Legal Publishing CL/JUR/8649/2015. 